Human Ethology Bulletin 33(3) - Special Issue to commemorate the life of Irenäus Eibl-Eibesfeldt (2018): 1-2

Words from the President of ISHE

\title{
FAREWELL AND THANK YOU
}

\section{S. Craig Roberts}

President, International Society for Human Ethology

Division of Psychology, University of Stirling, Stirling, United Kingdom

craig.roberts@stir.ac.uk

It is my responsibility to open this special issue of Human Ethology Bulletin, which is produced in commemoration of Irenäus EiblEibesfeldt and in recognition of his immense contribution to our understanding of human behaviour.

Unlike those others who have so generously and eloquently written in this issue, I did not meet or know Renki. I have no personal anecdotes about him and can claim no special insight into his research. But in this sense, I may perhaps represent many others among our readership who know him solely by reputation, from reading his work, or who have benefitted from his energy in other ways.

Isaac Newton famously wrote about being able to see further by standing on the shoulders of giants, a phrase he adapted from earlier 
philosophers and which has now become the motto of Google Scholar. We will read later in this issue about how Renki was heavily influenced by working with Konrad Lorenz and others. In the same way, Renki's work provides a very firm footing for much of what we human ethologists investigate today.

In reading Wulf Schiefenhoevel's obituary, I was particularly struck by Renki's strategic selection of five 'model' cultures on which he based much of his research. On one hand, it is reminiscent of Louis Leakey's very successful approach to gaining a detailed overview of behaviour across great ape species. On the other, it particularly brought to mind the recent 'epiphany' in psychology: that decades of research on western (WEIRD) undergraduates can produce neither a comprehensive picture of human universals nor help us to understand the interesting variation that is generated by different socioecologies. In this, Renki was decades ahead of his time. We would do well to revisit his work regularly.

As current President of the International Society for Human Ethology, I am also grateful for his foresight in co-founding this Society, along with William Charlesworth and Daniel Freedman. The first learned society dedicated to academic research on human behaviour in biological perspective, a full sixteen years ahead of the Human Behavior and Evolution Society, this was a prescient step. Over the almost fifty years since then, the Society has played a key role in shaping the field. It has done this through the Bulletin, and through its Biennial Congresses and more recently the Summer Institutes, which have provided a forum for dissemination and discussion in a conspicuously positive and collegial atmosphere. In this way, many hundreds of researchers owe Renki a great debt of thanks.

On behalf of all these people, we say

"Farewell, and thank you". 